https://helda.helsinki.fi

\title{
Increased psychiatric diagnoses and service use in childhood
}

\section{Korhonen, Marie}

2018-03

Korhonen , M \& Korhonen , L 2018 , ' Increased psychiatric diagnoses and service use in childhood ' , The Lancet psychiatry , vol. 5 , no. 3 , pp. 191-192 . https://doi.org/10.1016/S2215-0366(18)30039-7

http://hdl.handle.net/10138/300989

https://doi.org/10.1016/S2215-0366(18)30039-7

publishedVersion

Downloaded from Helda, University of Helsinki institutional repository.

This is an electronic reprint of the original article.

This reprint may differ from the original in pagination and typographic detail.

Please cite the original version. 


\section{Kristiina Kompus}

Department of Biological and Medical Psychology, University of Bergen, Bergen, Norway; NORMENT Center of Excellence, University of Oslo, Oslo, Norway and School of Natural Sciences and Health, Tallinn University, Tallinn, Estonia

kristiina.kompus@uib.no

I declare no competing interests.

1 Morina N, ljntema H, Meyerbröker L, Emmelkamp PMG. Can virtual reality exposure therapy gains be generalized to real-life? A meta-analysis of studies applying behavioral assessments. Behav Res Ther 2015; 74: 18-24

2 Opriş D, Pintea S, García-Palacios A, Botella C, Szamosközi ş, David D. Virtual reality exposure therapy in anxiety disorders: a quantitative meta-analysis. Depress Anxiety 2012; 29: 85-93.

3 Parsons TD, Rizzo AA. Affective outcomes of virtual reality exposure therapy for anxiety and specific phobias: A meta-analysis. J Behav Ther Exp Psychiatry 2008; 39: 250-61.
4 Rus-Calafell M, Garety P, Sason E, Craig TJK, Valmaggia LR. Virtual reality in the assessment and treatment of psychosis: a systematic review of its utility, acceptability and effectiveness. Psychol Med 2018; 48: 362-91.

5 Gega L, White R, ClarkT, Turner R, Fowler D. Virtual environments using video capture for social phobia with psychosis. Cyberpsychol Behav Soc Netw 2013; 16: 473-79

6 Pot-Kolder RMCA, Geraets CMW, Veling W, et al. Virtual-reality-based cognitive behavioural therapy versus waiting list control for paranoid ideation and social avoidance in patients with psychotic disorders: a single-blind randomised controlled trial. Lancet Psychiatry 2018; published online Feb 8. http://dx.doi.org/10.1016/S2215-0366(18)30053-1.

7 Freeman D, Bradley J, Antley A, et al. Virtual reality in the treatment of persecutory delusions: randomised controlled experimental study testing how to reduce delusional conviction. BrJPsychiatry 2016; 209: 62-67.

\section{Increased psychiatric diagnoses and service use in childhood}

Child development and mental health are complex interwoven processes influenced by biological, environmental, and cultural factors. This inter-relationship can change with time, necessitating adjust-ment of the use and availability of health resources. To know which adjustments are necessary, and to what extent, proper knowledge and insights about the prevailing situation are needed. In The Lancet Psychiatry, David Gyllenberg and colleagues ${ }^{1}$ provide some insights into these questions by exploring the incidence of psychiatric diagnosis in two Finnish birth cohorts-one born in 1987, the other in 1997-that were followed up from age 12 years to age 18 years. The authors report increased absolute and cumulative incidences in specialised service use for psychiatric disorders. A significant (ie, $p<0.05$ ) increase was found in 13 of 17 studied specific diagnostic classes in both sexes. The largest absolute increases occurred in depression and anxiety disorders among girls and in emotional and social interaction disorders and attention deficit hyperactivity disorder among boys.

What could explain the increased incidence of psychiatric diagnoses? As pointed out by Gyllenberg and colleagues, the proportion of adolescents with psychiatric problems in the general population has been rather stable. Adjustment for family-related and sociodemographic covariates did not explain the increases, suggesting that factors other than those recorded in registers could be important. In Finland, major changes in clinical routines during the past decade have included a shift from inpatient to outpatient care, substantially faster access to treatment, and more systematic use of structured diagnostic methods. Furthermore, educational actions have been taken to increase awareness of mental health problems among children and adolescents, and stigma associated with psychiatric problems has lessened as a result of many public and social media campaigns. Gyllenberg and colleagues also explored the incidence of death by suicide among adolescents. The frequency of suicide was low, but data suggested that most adolescents had not used psychiatric services before their suicide. This finding is alarming, and raises questions about whether the Finnish health system is able to detect or help those most in need.

Nationwide registers are powerful tools for analysis of trends in clinically important issues such as service use. Accurate and uniform use of clinical diagnoses and careful reporting procedures are prerequisites for the feasibility of data. In the future, more attention should be paid to finding easy and intelligible ways to collect data and to use these data to inform clinical decision making, clinical management, and policy making.

Gyllenberg and colleagues' findings are in line with those of previous studies suggesting an increase in clinical diagnosis and treatment of child and adolescent psychiatric disorders. ${ }^{2}$ Yet evidence suggests that only some of the children in need actually receive support from mental health services. ${ }^{3}$ Thus the challenge is to fit supply with demand. Not everyone who needs support
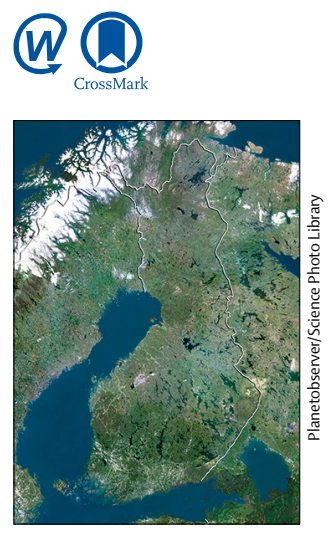

Published Online January 18, 2018 http://dx.doi.org/10.1016/ S2215-0366(18)30039-7 See Articles page 227 
For more on the Finnish Mental Hub see www.mentalhub.fi can be cared for in specialised health care, which emphasises the need for other measures, such as earlyaccess services (eg, the headspace centres established in Australia). ${ }^{4}$ Every effort should be made to disseminate community-based preventive interventions like those described for early behaviour problems. ${ }^{5}$ Additionally, digital services, such as the recently launched Finnish Mental Hub system-which offers psychoeducation, self-help programmes, and web-based therapies-could be flexible, feasible, and cost-effective alternatives. To ensure transition towards patient-centered and demand-driven health and social care, attention should be paid to patient segmentation and service design. ${ }^{6,7}$

Recognition of changes in the incidences of psychiatric problems among all age groups provides a basis for adjustment of resources and treatment to patient needs. Equally important is an understanding of the underlying causes of the increase in psychiatric diagnosis at the biological, environmental, and cultural level. The epidemiological work by Gyllenberg and colleagues is important, and their findings should be studied further in other cohorts, prospective samples, and different age groups. Studies should also be done to understand the crucial and moderating factors related to the psychopathology underlying psychiatric problems. Improved insight into the interplay between environmental and biological factors can lead to better diagnosis, treatments, and prevention of mental health problems in early childhood through adolescence.

\section{*Marie Korhonen, Laura Korhonen}

Child Psychiatry, Tampere University, Laakarinkatu, Tampere 33100 Finland (MK); Child Psychiatry, Helsinki University Hospital, Helsinki, Finland (MK); Children's Hospital, University of Helsinki, Helsinki, Finland (LK); Helsinki University Hospital, Helsinki, Finland (LK); and Center for Social and Affective Neuroscience, Department of Clinical and Experimental Medicine and Department of Child and Adolescent Psychiatry, Linköping University, Linköping, Sweden marie.korhonen@fimnet.fi

MK has received a grant from Lastentautien tutkimussäätiö. LK declares no competing interests.

1 Gyllenberg D, Marttila M, Sund R, et al. Temporal changes in the incidence of treated psychiatric and neurodevelopmental disorders during adolescence: a register-based analysis of two national Finnish birth cohorts. Lancet Psychiatry 2018; published online Jan 18. http://dx.doi.org/10.1016/S2215-0366(18)30038-5.

2 Collishaw S. Annual research review: secular trends in child and adolescent mental health. J Child Psychol Psychiatry 2015; 56: 370-93.

3 Costello EJ, He J, Sampson NA, Kessler RC, Merikangas KR. Services for adolescents with psychiatric disorders: 12 -month data from the National Comorbidity Survey-Adolescent. Psychiatr Serv 2014; 65: 359-66.

4 McGorry P, Bates T, Birchwood M. Designing youth mental health services for the 21st century: examples from Australia, Ireland and the UK. BrJ Psychiatry 2013; 202 (suppl): 30-35.

5 Sourander A, McGrath PJ, Ristkari T, et al. Internet-assisted parent training intervention for disruptive behavior in 4-year-old children. A randomized clinical trial. JAMA Psychiatry 2016; 73: 378-87.

6 Lillrank P, Groop PJ, Malmström TJ. Demand and supply-based operating modes - a framework for analyzing health care service production. Milbank Q 2010; 88: 595-615.

7 Lynn J, Straube BM, Bell KM, Jencks SF, Kambic RT. Using population segmentation to provide better health care for all: the "Bridges to Health" model. Milbank Q 2007; 85: 185-208.

\section{(1) Ageism and suicide prevention}

Published Online November 22, 2017 http://dx.doi.org/10.1016/ S2215-0366(17)30472-8
Suicide in old age is often considered to be the result of a rational decision. Frailty, dependence on others, loss of a partner, and loneliness are seen as reasons that might explain many instances of suicide. Similarly, suicide can be interpreted as a legitimate exit in case of dramatic changes in social status and role. Ageistic views tend to consider depression as a normal feature of the ageing process, and advanced age as the antecedent of an anticipated and definitive ending. Accumulation of physical illnesses and disabilities, life events, and losses can be seen as the so-called right cause to step out of this stage of life. This interpretation-the ultimate corollary of senectus ipsa morbus-overlaps with the idea of elderly people being overwhelmed by their emotions, and seeing suicide as their only escape from an unbearable situation.
Depression is an important risk factor for suicidal behaviour, even in individuals of a very advanced age ${ }^{1}$ however, its role could have been overestimated or generalised more than necessary by making it the scapegoat of any situation related to suicide. In fact, excessive simplification of problems, so that they are all attributable to depression, can induce a rigid prescriptive approach. For instance, this perception often restricts treatment of elderly people showing suicidal behaviour to the recommendation of an antidepressant drug. Hence, the multifactorial nature of an individual's crisis could be interpreted from a narrow point of view. From the perspective of suicide prevention, a careful and prudent approach is always preferable to considering life events-and reactions such as suicide-as inevitable. Such a passive approach 